\title{
A MOBILIZAÇÃO SOCIAL E RESPOSTA COMUNITÁRIA LGBT À AIDS - ITINERÁRIOS REFLEXIVOS ${ }^{1}$
}

\author{
Marcio Rodrigo Vale Caetano* \\ Alexsandro Rodrigues** \\ Cláudio Nascimento Silva***
}

\begin{abstract}
Resumo: $\mathrm{O}$ artigo se propõe a analisar, panoramicamente, as redes de solidariedade e a emergência de grupos e organizações não-governamentais de lésbicas, gays, bissexuais, travestis e transexuais (LGBT) a partir das lutas comunitárias em resposta à epidemia de HIV/AIDS nas décadas de 1980 e 90. Para tanto, buscamos inspiração no estilo ensaístico com vistas a estimular o debate. Todas as considerações permitem reafirmar o ensaio como uma dissertação pouco extensa, na qual o/a autor/a constrói o seu objeto através de um encadeamento de raciocínios lógicos e fundamentados que estruturam sua argumentação. Ancorados nesta ideia, entendemos que, se por um lado as primeiras pessoas identificadas com HIV eram homens gays, reforçando o estigma sobre a população, por outro, as respostas comunitárias dadas à epidemia e os rumos do movimento LGBT foram responsáveis por levar à tona o debate sobre as homossexualidades e outros modos dissidentes de viver a heterossexualidade e a(s) masculinidade(s). Consideramos que a sociedade civil representou um importante ator no enfrentamento à epidemia auxiliando a construção de políticas públicas.
\end{abstract}

Palavras-chave: HIV/AIDS. LGBT. Movimento Social. Resposta Comunitária.

\section{Introdução}

Este artigo foi produzido buscando intercambiar tempos e experiências comuns de seus autores em seus encontros com a temática anunciada no título. Buscamos fazer uma conversa cuidadosa com os discursos teóricos e políticos que nos fizeram assumir uma vida implicada com os movimentos sociais ${ }^{2}$ e com a academia, no sentido de produzirmos aprendizagens solidárias com aquilo que nos tomava como alvo e causa: o HIV. Nesse sentido,

\footnotetext{
${ }^{1}$ Este trabalho possui apoio do CNPq e integra as pesquisas de pós-doutorado desenvolvidas no Programa de Pósgraduação em Educação da Universidade do Estado do Rio de Janeiro (Proped-UERJ) com financiamento da CAPES.

* Líder do Nós do Sul - Laboratório de Estudos e Pesquisas sobre Identidades, Currículos e Culturas, doutor em Educação (UFF, 2011) e docente na Universidade Federal do Rio Grande (FURG).

**Doutor em Educação (UFES, 2009). Docente Permanente no Programa de Pós-Graduação em Psicologia Institucional (PPGPSI/UFES) e no Centro de Educação. Coordenador do Grupo de Estudo e Pesquisas em Sexualidades (GEPSs/UFES) e do Núcleo de Pesquisa em Sexualidade (NEPS/UFES).

*** Licenciado em Filosofia (UNISUL, 2018) e ativista no Grupo Arco-Íris de Cidadania LGBT.

2 Reconhecendo a multiplicidade de leituras e definições, estamos entendendo a categoria "movimento social" como sendo ações coletivas de coletivos de sujeitos organizados, que objetivam alcançar alterações sociais, culturais e/ou econômicas por meio do embate político, conforme seus valores e ideologias dentro de uma determinada sociedade e de um contexto específico, permeados por tensões sociais.
} 
vamos sendo embalados por forças combativas frente às barbáries que, nos últimos 40 anos, se materializaram nos cotidianos de mortes e ameaças à população LGBT (Lésbica, Gay, Bissexual, Travesti e Transexual). Assim, fomos orientando a ressignificação em torno dos processos de aprendizagens com o corpo, o desejo, a identidade política e a vida ao longo da história brasileira. Entre várias possibilidades, inspirados em João Guimarães Rosa, nós estamos narrando nossa versão do conto:

\footnotetext{
A lembrança da vida da gente se guarda em trechos diversos, cada um com seu signo e sentimento, uns com os outros acho que nem se misturam. Contar seguido, alinhavado, só mesmo sendo as coisas de rasa importância. De cada vivimento que eu real tive, de alegria forte ou pesar, cada vez daquela hoje vejo que eu era como se fosse diferente pessoa. Sucedido desgovernado. Assim eu acho, assim é que eu conto. [...] Tem horas antigas que ficaram muito mais perto da gente do que outras, de recente data. (ROSA, 2001, p.114-115).
}

Seguindo os contos de nosso conto, iniciamos lembrando que uma das primeiras experiências com textos feministas que nos levaram a refletir a trajetória do movimento LGBT no pós-epidemia de AIDS foi o escrito "O Manifesto Ciborgue”, de Donna Haraway (2000). Dentre tantas questões que nos instigaram naquele momento, a noção da escrita enquanto instrumento de resistência e existência foi muito impactante, considerando, inclusive, as diferentes vivências e ativismos.

Desde então, esse viés político de escrita, profundamente inspirado nas feministas, passou a orientar a forma como imaginamos desenvolver nossas trajetórias políticoprofissionais na gestão de políticas públicas, nas fileiras do ativismo social, nos modos como nos constituímos docentes e, principalmente, em nossas produções acadêmicas. Este processo foi interessantíssimo, sobretudo quando retornamos às discussões de Haraway (2000) e Bell Hooks (2013) sobre a escrita para o coletivo de sujeitos que, de alguma forma, viveram/vivem sob a imposição de condições de subalternidade que os querem inexistentes na lógica cidadã do mundo liberal e/ou que convivem com o silenciamento de suas posições sobre a história. Nesse grupo, localizamos as lésbicas, os gays, as/os bissexuais, as travestis e as/os transexuais.

Neste percurso de escrita e construção de existência, acompanhados de nossas leituras de Haraway (2000), vimos que as identidades são contraditórias e as narrativas que buscam interpretá-las ficam ainda mais complexas quando consideram as intersecções de classe, identidade de gênero, raça, faixa etária e regionalidade, todas profundamente mediadas pelas dinâmicas do capitalismo colonialista e patriarcal. Diante desse cenário, este artigo, escrito a seis mãos calejadas pelo ativismo e pela vida na periferia da Baixada Fluminense - Rio de 
Janeiro, propõe-se a debater panoramicamente, dentre tantas outras possibilidades, nossas leituras sobre as tensões e acordos constituídos a partir da visibilidade LGBT com a institucionalidade e ampliação do movimento LGBT, o interesse midiático e as políticas de enfrentamento à epidemia de AIDS, sobretudo, a partir da década de 1990.

Neste caminho, estamos tecendo cruzamentos e fios de histórias que ficaram momentaneamente esquecidos no e com o tempo de nossas memórias e documentos guardados em nossos arquivos pessoais. O que realizamos não foi somente trazer as fontes pesquisadas, mas, também, é nossa intenção possibilitar a escrita, que poderá estimular naqueles/as que dela se sintam personagens, a elaboração de outras narrativas, para que se produzam sentidos e tecidos históricos diferenciados. Ainda que o recorte espacial que orientou a análise seja as experiências vividas com o movimento social LGBT do Rio de Janeiro, cremos que as experiências aqui debatidas tenham de alguma forma sido vividas por várias das organizações AIDS e LGBT no Brasil.

\section{Do caos a emergência LGBT}

No Brasil, a homossexualidade deixou de se configurar como doença nos instrumentos médicos, mais precisamente como desvio mental e transtorno sexual - conforme o código 302.0 da Classificação Internacional de Doenças (CID), elaborado pela Organização Mundial de Saúde e adotado no país - em fevereiro de 1985. Essa alteração foi fruto de uma intensa campanha liderada, sobretudo, pelo antropólogo Luiz Mott e o advogado João Antônio Mascarenhas ${ }^{3}$ junto ao Conselho Federal de Medicina (CFM) que, por resolução, retirou a homossexualidade da lista de doenças.

É importante dizer que o CFM seguiu a American Psychiatric Association que, já em 1973, afirmou que a homossexualidade não tinha nenhuma ligação com qualquer tipo de patologia e propôs a sua retirada do Manual de Diagnóstico e Estatístico de Transtornos Mentais (DSM-IV). O CFM antecipou a Organização Mundial de Saúde (OMS) que, somente no dia 17 de maio de 1990, reunida em Assembleia Geral, retirou a homossexualidade de sua lista de doenças mentais, declarando que ela não constituía um distúrbio, uma doença ou

\footnotetext{
${ }^{3}$ Mott e Mascarenhas, de diferente forma e intensidade, lideraram essa campanha em várias frentes e acabaram por receber apoio de entidades, como a Sociedade Brasileira para o Progresso da Ciência (SBPC), a Associação Brasileira de Antropologia (ABA) e a Associação Nacional de Pós-Graduação em Ciências Sociais (ANPOCS). Para saber sobre a mobilização do movimento social contra a presença da homossexualidade no CID e sua configuração histórica no Código, ver: LAURENTI, Ruy. Homossexualismo e a Classificação Internacional de Doenças. Revista de Saúde Pública. vol.18, n. 5. São Paulo, Oct. 1984.
} 
perversão. Entretanto, somente em 1993, através de forte pressão dos movimentos sociais LGBT, a OMS retirou o termo "homossexualismo" (que reforçava uma concepção de doença, já que era assim descrita no CID) e adotou o termo homossexualidade. À decisão do CFM, seguiu-se a Resolução nº 001/ 99, do Conselho Federal de Psicologia (CFP, 1999), que instruiu profissionais da psicologia a se posicionarem contrários/as às discriminações e não se colocarem dispostos/as a participarem de eventos e serviços que proponham o tratamento de cura à homossexualidade (CAETANO, 2016).

Entretanto, mesmo após a despatologização da homossexualidade pelo CFM nos anos 1980, outros discursos buscaram novamente levar a prática homossexual aos limites impostos pelo discurso médico. A desinformação aliada à publicidade dos primeiros diagnósticos do HIV/AIDS foi direcionada, de imediato, ao público homossexual masculino. Nesse contexto, assumir publicamente esta identidade era reconhecer também a tutela do "câncer gay" ou "peste gay”, como ficou conhecida a doença na maior parte desta década no mundo ${ }^{4}$.

É inegável que o temor da epidemia estava presente em todas as relações sociais, inclusive entre homens homossexuais. A desinformação sobre a epidemia nas décadas 1980 e 90 construiu, individualmente, sentimentos e táticas diferenciadas para negociar o desejo por parceiros do mesmo sexo. Cada sujeito, dentro do que a epidemia lhe trazia enquanto imagem e consequência para suas vidas, deslumbrou e construiu sua forma de driblar o contágio, a exemplo de sexo sem penetração e/ou ao evitar parceiros estadunidenses ou brasileiros que regressaram de viagem aos EUA, país onde foram identificados os primeiros casos.

Com a história da epidemia de AIDS, sem dúvida, é possível entender a massificação da categoria "gay". A isso atribuímos dois fatores, no Brasil: o primeiro foi a emergência nos Estados Unidos (EUA) do movimento gay e sua influência cultural nos demais países ocidentais; o segundo, é a epidemia, por vezes, discursiva ${ }^{5}$, da AIDS, nos anos $1980^{6}$. No Brasil,

\footnotetext{
${ }^{4}$ Um dos primeiros casos emblemáticos da epidemia de AIDS no Brasil, em particular, foi a publicidade da sorologia do estilista Marcus Vinícius Resende Gonçalves, popularmente conhecido como Markito. Ele foi um dos nomes mais influentes da moda brasileira nos anos de 1970.

5 Chamamos de epidemia discursiva a proliferação desencontrada de enunciados sobre a doença, ocorrida, sobretudo, nos anos 1980.

${ }^{6} \mathrm{Se}$, de início, a epidemia foi identificada como $4 \mathrm{H}$, devido ao número expressivo de haitianos, heroinômanos, hemofílicos e homossexuais que eram portadores da síndrome, posteriormente, ela foi nomeada como "câncer gay". Essa situação ocorreu porque quando os primeiros casos de HIV apareceram nos EUA, os doentes desenvolviam manchas escuras no corpo - sintoma de um tipo raro de câncer, "sarcoma de Kaposi". Nessa época, as manchas escuras que estavam afetando/marcando os gays fizeram com que a AIDS fosse nomeada de "câncer gay".
} 
não diferentemente dos EUA, a terminologia "gay" tem no movimento social ${ }^{7}$ e na AIDS seus principais difusores $^{8}$ (GREEN, 2000).

A energia e impulso por classificar e categorizar homens e mulheres que se relacionavam/relacionam afetivo-sexualmente com pessoas do mesmo sexo ou que rompem a fronteira do gênero heterodesignado, a exemplo da pessoa transexual, têm levado intelectuais e ativistas a afirmarem que o surgimento de distintas categorias de seres sexuais ao longo dos três últimos séculos XIX, XX e XXI é consequência de um esforço contínuo de alcançar o controle social. Desde logo, isto contém um elemento de verdade. Não obstante, assim como pensa Norma Mogrovejo (2008), consideramos que é mais contundente ver o surgimento de identidades como produto da luta contra as normas prevalecentes, que indiscutivelmente têm efeitos diferentes sobre homens e mulheres.

Os sexólogos, e mais amplamente a ciência, não inventaram as existências correntemente entendidas como homossexualidade, transexualidade e intersexualidade. Contudo, ao descrever essas identidades, traduziram-nas a sua própria linguagem e as patologizaram ao mesmo tempo em que deram sentidos e legitimidades aos seus campos científicos. Ainda que a sexualidade assuma configurações fluidas, instáveis, inacabadas e, sobretudo, locais, a ampla divulgação e aceitação dessas categorias inscrevem-se em um contexto de crescente impacto da globalização econômica e social em que, cada vez mais, o que se sucede em uma cultura tem grande influência sobre as demais.

No momento em que a comunicação é intensamente facilitada pelos recursos tecnológicos, em que o turismo assume grande escala, o transporte é rápido e a migração local, nacional e internacional é cada dia mais massificada, dificilmente uma cultura consegue manter-se isolada. As transformações globais da economia e as interações culturais são sentidas nos lugares mais distantes dos grandes centros urbanos. Através de inúmeros recursos pedagógicos, a exemplo da televisão, filmes e redes sociais virtuais, somos capazes de acessar diversos estilos de vida. Nesses entrecruzamentos, as identidades LGBT e seus modos de vida, inventadas de forma efervescentes nas grandes cidades estadunidenses, europeias e latino-

\footnotetext{
7 O Grupo Gay da Bahia, fundado pelo antropólogo Luiz Mott, é a mais antiga associação de defesa dos direitos humanos gays no Brasil. Fundado em 1980, registrou-se como sociedade civil sem fins lucrativos em 1983.

8 Edward Macrae $(1990 ; 1987 ; 1982)$ nos apresenta interessantes discussões sobre os debates criados no interior dos movimentos sociais sobre a terminologia (auto)designativa a ser adotada no Brasil; como também, as sequelas do HIV na população homossexual.
} 
americanas, desafiam hoje as múltiplas maneiras de interação homossexual e heterossexual que existiam tradicionalmente nas sociedades ocidentais.

A política de emancipação das mulheres e a liberdade sexual assumiram diferentes formas em distintos países ou regiões no Brasil, mas não podemos ignorar que elas estão diretamente envolvidas com os acordos e tradições econômicas, legais e religiosas. A epidemia de AIDS pode ter apresentado impacto distinto em diversas populações, de acordo com muitos fatores, porém não cabe nenhuma dúvida de que ela foi uma ameaça em escala mundial que redimensionou os modos de vida da população, sobretudo, a LGBT.

Como se não bastassem os discursos que alimentavam a construção de um corpo doente aliados à repressão social/policial que restringia o afeto ou sociabilidade, na maior parte do século XX (GREEN, 2000), a população LGBT foi tatuada com outras marcas, agora as oriundas da epidemia. A agregação da doença a discursos religiosos aprofundava a ideia de que o amor homossexual era pecado e que, portanto, a AIDS seria o castigo de Deus.

É inegável que a epidemia estava nos discursos produzidos nas mais variadas esferas sociais e eles se acentuavam com o contágio de personalidades e artistas que eram vitimados por suas sequelas. O temor de contágio com o vírus HIV, assim como as discussões sobre a doença "homossexualismo", orientou desejos, ensinou práticas, produziu outras variadas formas de relacionamentos e modelou corpos ${ }^{9}$. As notícias e a desinformação alastravam a violência e garantiam manchetes nos jornais (CÂMARA, 2002). Entretanto, os estereótipos produzidos em torno da AIDS e alocados aos corpos homossexuais e trans (travesti e transexual) são apenas um lado desse cenário. De outro, eles também impulsionaram a necessária mobilização para responder às demandas criadas em torno da doença e da manutenção da vida de portadores/as do vírus HIV.

Do ponto de vista simbólico, a epidemia de AIDS foi, sem dúvida, a maior "mancha" realizada na masculinidade hegemônica nos últimos 40 anos. Em quase toda a década de 1980 e 90, ela denunciava ou aproximava, no plano especulativo, os seus portadores às práticas homossexuais. Quem de nós, ao viver nessas décadas e ao saber do diagnóstico de um conhecido identificado como heterossexual, não realizou a clássica pergunta: Como ele pegou? E deduziu: "Ele é gay!".

\footnotetext{
${ }^{9}$ Sobre as consequências culturais ocorridas com o HIV nas redes de sociabilidades "gay", ver Richard Parker \& Cristina Pimenta (2004).
} 
O HIV/AIDS produziu ressonâncias complexas nos comportamentos sociais, o tempo inicial da epidemia era de excessos. A fogueira da inquisição fora reacendida nos idos dos anos 1980, e se apresentava para alguns moralistas como resposta da revolução sexual e da fragilidade da família mononuclear. Jeffrey Weeks (2001, p.37) nos faz lembrar que:

\begin{abstract}
Numa época na qual assistimos como nunca antes, a celebração de corpos saudáveis perfeitamente harmoniosos, uma nova síndrome emergiu e devastou o corpo. Estava estreitamente conectada com o sexo - com atos através dos quais o vírus HIV poderia ser transmitido. Muitas pessoas, e não apenas a imprensa sensacionalista, apresentava a AIDS como um efeito necessário do excesso sexual, como se os limites do corpo tivessem sido testados e não tivessem passado no teste da perversidade sexual. De acordo com os mais óbvios comentários, era a vingança da natureza contra aqueles que transgrediam seus limites. A suposição parecia ser que o corpo expressa uma verdade fundamental sobre a sexualidade. Mas que verdade poderia ser esta? Sabemos agora que o vírus HIV, responsável pelo colapso das imunidades do corpo, causando a AIDS, não é seletivo no seu efeito. Ele afeta heterossexuais e homossexuais, mulheres e homens, jovens e velhos. Além disso, ao mesmo tempo, ele não afeta todas as pessoas nessas categorias, nem mesmo necessariamente os/as parceiros/as das pessoas infectadas com HIV. Contrair o HIV é, em parte, uma questão de acaso, mesmo para aquelas pessoas que estão envolvidas no que agora chamamos de atividades de alto risco.
\end{abstract}

No cotidiano da epidemia, era comum duvidar da masculinidade heterossexual de um sujeito somente porque ele vivia com o HIV. Em outras palavras, na década de 1980 e grande parte da década de 1990, a sigla AIDS e a homossexualidade masculina eram cotidianamente entendidas como sinônimas. Foi assim que várias personalidades e artistas foram forçadamente obrigadas a fazer seus out' $\mathrm{s}^{10}$. Um dos casos mais emblemáticos e que teve sua repercussão no Brasil foi a do ator americano Rock Hudson ${ }^{11}$. Sua trajetória artística em Hollywood foi produzida em torno dos símbolos de virilidade e masculinidade (vale destacar que estas nomeações eram exclusivas à heterossexualidade) e ele protagonizou inúmeros filmes, programas de televisão e algumas peças teatrais ao lado de atrizes, como Yvonne De Carlo, Elizabeth Taylor e Doris Day. Encarado como símbolo de beleza e dono de um tom de voz grave, Rock Hudson foi uma das maiores personalidades que marcaram a epidemia de AIDS e, talvez, um dos maiores golpes no ideal de masculinidade.

\footnotetext{
10 Movimento de assumir publicamente uma prática homossexual ou uma identidade gay, bissexual e lésbica.

$11 \mathrm{O}$ ator esteve no Rio de Janeiro em 1958, no auge da popularidade, quando a imprensa nacional insistiu em fabricar um romance entre ele e a atriz Ilka Soares. Sobre a visita de Hudson ao Brasil e sua aparição ao lado da atriz brasileira, ver Green, 2000. Em 2009, os cineastas alemães Andrew Davies e André Schafer produziram o documentário "Rock Hudson - dark and handsome stranger". O documentário, que no Brasil recebeu o nome de "Rock Hudson: Um Estranho Sombrio e Belo", narra a história das sequelas do HIV na vida do galã, que assumiu sua identidade gay nos últimos anos de vida.
} 
Figura 1 - Rock Hudson, the real story shocking reason he hid Aids for a year ${ }^{12}$

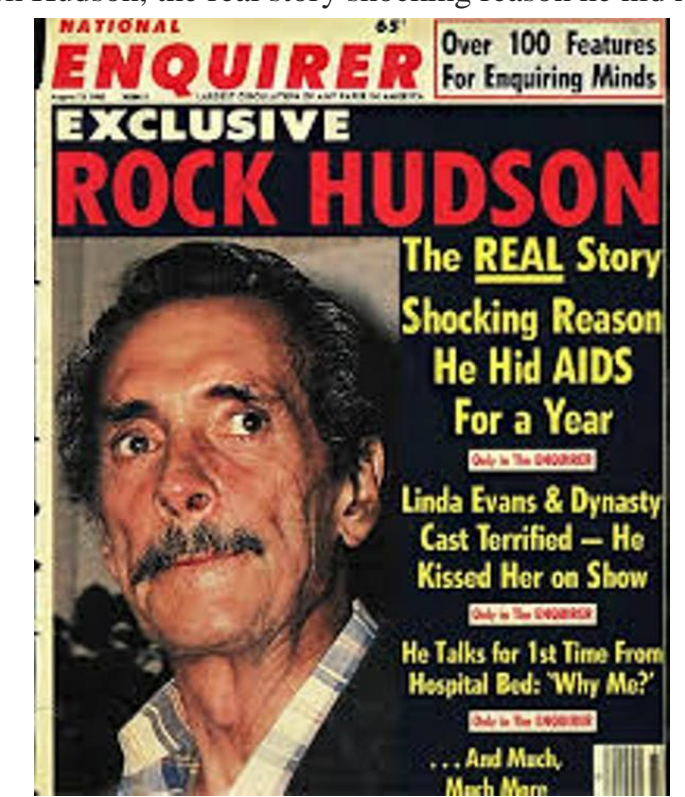

Fonte: Jornal National Enquirer. Nova Iorque: National Enquirer, 13 de agosto de 1985. Capa. (Arquivo Pessoal)

A imprensa sensacionalista, semelhante ao Brasil, não hesitou em estampar as imagens degradantes com pessoas que viviam com AIDS, a exemplo daquilo que o tabloide estadunidense National Enquirer fez com Rock Hudson. Através do escândalo, a epidemia da AIDS recebeu publicidade maciça e desencadeou uma primeira onda de solidariedade e de políticas de saúde. Particularmente, no Brasil, várias personalidades que viveram com o HIV ganharam muito destaque. Não diferentemente de Rock Hudson, inúmeras personalidades artísticas masculinas eram vendidas como símbolos de homens galãs, sedutores e viris. Galãs de telenovelas, como Thales Pan Chacon, Caíque Ferreira e Lauro Corona, assumiram ou tiveram seus diagnósticos de HIV divulgados na imprensa. Entretanto, os casos de maior relevo midiático foram de Renato Russo, Lauro Corona e Cazuza.

Os desdobramentos da AIDS em Cazuza e no ator Lauro Corona foram acompanhados mais de perto pela população. No caso de Lauro Corona, os boatos surgiram na imprensa em janeiro de 1989, quando o ator pediu afastamento, alegando estafa, da telenovela Vida Nova, de Benedito Ruy Barbosa, na qual era protagonista ${ }^{13}$. Ao voltar, dois meses depois, para finalizar a telenovela, bem mais magro e com uma visível queda de cabelo, os boatos tornaram-se mais fortes. Sua aparência era o atestado de sua enfermidade, e o HIV era a prova das especulações de sua prática homossexual. Cazuza foi o símbolo, ou melhor, a personalidade

12 Rock Hudson, a verdadeira história chocante razão que ele escondeu AIDS por um ano. Tradução livre.

13 Sobre as telenovelas da Rede Globo de televisão, ver: DICIONÁRIO DA TV GLOBO, 2003. 
vivendo com AIDS mais explorada pela mídia no Brasil. As formas como suas apresentações eram exploradas denunciavam as sequelas daquilo que era marcado como acometimentos da doença. Esta situação foi tão fortemente utilizada pela imprensa que a Revista Veja, de abril de 1989, afirmava na capa de publicação semanal que o artista agonizava em praça pública.

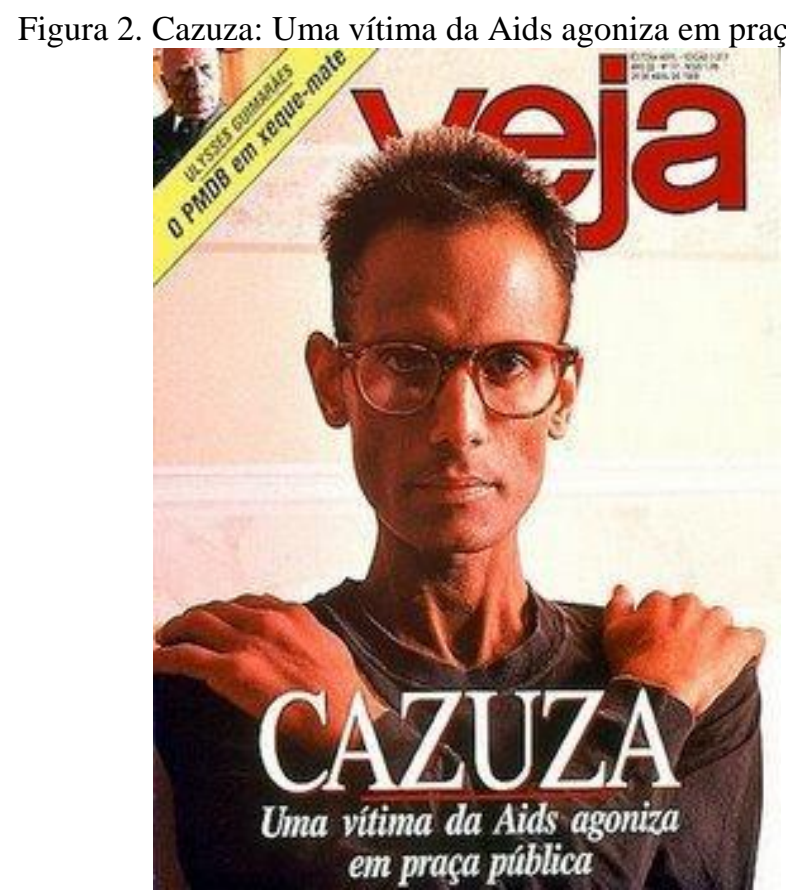

Fonte: REVISTA VEJA. São Paulo: Ed. Abril, Edição 1077, Ano 22, No. 17, abril. 1989. Capa. (Arquivo Pessoal)

De fato, esse cenário escandaloso da mídia foi apenas o segundo lado dessa enfermidade, que foi uma das maiores responsáveis, ao lado da pílula anticoncepcional, das mudanças culturais em torno do sexo, no século XX. Para além de borrar as masculinidades heterossexuais e homossexuais ${ }^{14}$, o contágio com o HIV, a necessidade de medicamentos, a partida de pessoas amigas e familiares criaram em torno da epidemia uma rede de solidariedades que nutriu de força vários movimentos sociais. O luto acompanhou o imediato surgimento da AIDS, entretanto, a resposta também foi dada pelas próprias vítimas ${ }^{15}$.

A epidemia de AIDS obrigou as inúmeras esferas sociais a olharem para a sexualidade e, de alguma forma, discuti-la. Independentemente dos paradigmas que orientaram essas

\footnotetext{
14 O "out" de vários símbolos masculinos do universo artístico, como Rock Hudson, Fred Mercury, Lauro Corona, entre vários outros, não somente representou borrar a masculinidade heterossexual com a prática homossexual e a identidade gay. Mas, também, que a homossexualidade hegemônica, marcada e definida pela frustração das expectativas de gêneros, foi borrada pelos signos da heterossexualidade. Em outras palavras, um homem com todos os símbolos viris de Rock Hudson podia ser gay. Esse é outro aspecto da crise dos marcadores da masculinidade hegemônica.

15 Sobre a mobilização comunitária e as criações dos programas brasileiros de enfrentamento ao HIV, ver: Ézio Távora dos Santos Filho (2002).
} 
discussões, a sexualidade, o desejo e as práticas sexuais passaram a estar presentes nas agendas e preocupações sociais, religiosas, estatais e familiares. Esse cenário produziu outros movimentos e outras redes discursivas de controle e modulação de práticas de sociabilidade e afetivo-sexuais. Com frases imperativas, a exemplo de "Use camisinha", as sexualidades ganharam uma centralidade discursiva e profundamente pragmática e intervencionista nas políticas públicas de prevenção ao HIV.

A re-emergência e o fortalecimento do então movimento social homossexual, a partir da década de 1990, foi algo que ocorreu como uma das consequências das políticas adotadas ao enfrentamento à AIDS. Contudo, é importante destacar que a aproximação entre a agenda de combate à AIDS e as organizações de direitos civis nas décadas de 1980 e 90 não foi algo automático. Mesmo com o fato de que a epidemia alcançasse toda população LGBT, seja pelo contágio com o HIV ou a (auto)repressão social e política, organizações emblemáticas, a exemplo de Triângulo Rosa, liderada por João Antônio Mascarenhas, havia tensões internas quando o assunto era a resposta comunitária à epidemia. Parte hegemônica do grupo entendia que a mobilização e as respostas à epidemia eram de responsabilidade das políticas governamentais.

$\mathrm{Na}$ lógica de desestigmatizar a homossexualidade, referenciada pela agenda masculina, lideranças negavam a ideia de assumir para o movimento social as ações de enfrentamento à epidemia. Não obstante ao cenário descrito, a AIDS tinha, inicialmente, fortes marcadores sociais que a aproximava da classe média viajada e bem-sucedida, o que produzia, em maior ou menor grau, rechaço em inúmeras lideranças influenciadas por suas leituras do ideário revolucionário socialista.

Assumir as agendas de enfrentamento à AIDS representava, dentre outras coisas, se aproximar da cadeia de estigmas que o movimento social buscava se dissociar. Isso não significa que, no interior das organizações, não existiam tensões entre as estratégias de visibilidade, enfrentamento à epidemia de AIDS e as conquistas de direitos civis. Câmara (2002), Andrade (2002) e Caetano (2016), de diferentes formas, irão debater como as organizações, a exemplo de Triângulo Rosa (década de 1980) e Arco-Íris (década de 1990), ambas do Rio de Janeiro, foram tensionadas pelo desejo de dissociar a homossexualidade masculina dos históricos estigmas a que era atrelada e pela necessidade de incidir na epidemia, à medida que suas lideranças também eram atingidas pelo contágio do HIV. O fato é que os 
movimentos homossexuais, posteriormente chamado LGBT ${ }^{16}$, desde suas emergências, na década de 1970, as quais foram amplamente apresentadas e discutidas no livro de Regina Facchini (2005), buscam "referências positivas" ${ }^{17}$ para configurar suas identidades políticas e sexuais ${ }^{18}$.

Se na década de 1980, o movimento social manteve-se hegemonicamente distante da agenda e possibilidades institucionais proporcionadas e financiadas pelas políticas públicas de AIDS, vale destacar, na data de 1986, a criação do então Programa Nacional de DST e AIDS do Ministério da Saúde. Na década de 1990, o quadro epidemiológico e a possibilidade de articular a agenda de defesa de direitos civis no enfrentamento à epidemia produziu uma promissora parceria entre os programas estaduais, municipais e, sobretudo, federal de HIV/AIDS com várias das organizações homossexuais, formadas, sobretudo, por homens. Esse quadro possibilitou a profissionalização e dedicação de inúmeros ativistas, sobretudo gays e trans, que associaram ao enfrentamento da epidemia de AIDS as bandeiras políticas de promoção da cidadania e direitos humanos (ANDRADE, 2002). Sendo assim, é importante ressaltar que a movimentação social articulada pelas entidades da sociedade civil, organizada na década de 1980, contribuiu para o estabelecimento de uma corrente, que se fortaleceu à medida que as reivindicações de direitos pressionaram os atores políticos para a tomada de ações que configuraram mais tarde a nova política de saúde.

A proliferação discursiva sobre a epidemia de AIDS, a insurgência das organizações não-governamentais, as políticas de financiamento contra o HIV, o interesse mercadológico com o nicho gay iniciado nos fins dos anos de 1990 e as investidas do mercado midiático contribuíram para a "pluralidade" e a massificação da visibilidade no imaginário social e foram fundamentais porque deslocaram os discursos sobre a população LGBT de seus marcadores estigmatizados. Contudo, há de se verificar que a projeção entre as identidades não ocorreu da

\footnotetext{
16 Usamos o plural, exatamente para descrever que o movimento é constituído por cinco identidades políticas e que em seu interior interagem forças e interesses divergentes e que disputam a hegemonia dos discursos adotados e priorizados no momento.

17 De modo geral, os movimentos sociais LGBT, encaram como referências positivas aquelas representações que contrariam as imagens que os associam à frustração de expectativas de gênero, à marginalidade, ao pecado e à doença.

18 Mesmo com a fluidez das identidades, não devemos perder de vista que os sujeitos se reúnem e reivindicam um nome comum porque visualizam nas apresentações dessas identidades ações que os unificam. Neste texto, quando as identidades LGBT emergirem, assumirão, por força das circunstâncias normativas que as regem, um caráter político, seja porque contraria a lógica heteronormativa ou porque se alia a ela, contrariando, portanto, as expectativas de transgressão.
} 
mesma forma e na mesma intensidade. O próprio deslocamento de "bicha", "sapatão" e "trava" ou "boneca", nomenclaturas popularmente usadas para designar LGBT, será no sentido de apagar estes marcadores referenciais de suas performatividades.

Mesmo com toda a pluralidade, a matriz de visibilidade hegemônica ao longo da história recente do emergente movimento LGBT é ancorada na projeção gay. Tal formatação auxilia as denúncias de androcentrismo feitas pelas lideranças lésbicas, mulheres bissexuais e trans ao movimento LGBT. Com base nesse discurso, se originaram várias organizações e redes que buscaram, entre outras coisas, demarcar suas especificidades nas agendas do movimento, a exemplo de Articulação Brasileira de Lésbicas, Liga Brasileira de Lésbicas e Articulação Nacional de Travestis, Transexuais e Transgêneros, todas reivindicando discutir suas especificidades frente ao denunciado controle gay do movimento (SELEM, 2007). Assim, indiscutivelmente, pode se afirmar enquanto fatores que possibilitaram o fortalecimento da identidade gay: a) os recursos de combate à epidemia de AIDS que financiaram exclusivamente as ações ligadas a essa política entre as populações gays, trans e outros homens que faziam sexo com homens (HSH); b) a cultura androcêntrica e patriarcal brasileira; e c) o desinteresse inicial dos mercados pelas lésbicas, mulheres bissexuais e trans, motivados pela renda superior dos homens.

Historicamente, as organizações lésbicas e de mulheres bissexuais, para acessar a política pública de financiamento de ações contra o HIV/AIDS, foram obrigadas a produzir subterfúgios agregando as suas ações de enfrentamento à epidemia, mulheres em situação de cárcere ou heterossexuais. Esse quadro, somado e retroalimentado à própria lógica patriarcal vivida no Brasil, auxilia suas sub-representações entre as lideranças que falam em nome do movimento social.

Ao interrogar as políticas públicas de enfrentamento à AIDS, é possível facilmente observar a importância que as redes sociais lideradas por LGBT assumiram enquanto elementos de processos de conflito e de coalizão político-administrativa nas execuções das ações contra a epidemia. Frey (2000), ao observar a realidade política das democracias ditas mais consolidadas, afirma que os membros das redes que tencionam a elaboração de políticas públicas tendem a disputar entre si. Contudo, a rivalidade não determina o fim de pactos de coalisão. A solidariedade, segundo o autor, é, sem dúvida, o que lhes possibilita a defesa e a ação contra os elementos políticos que são determinados como concorrentes aos interesses das redes. No caso brasileiro, as lutas pelos recursos financeiros da AIDS tornaram-se particularmente acirradas, quando pensamos em seus desdobramentos e impactos no 
movimento LGBT. Assim foi comprometida, por vezes, a capacidade de articulação das identidades que integravam os movimentos sociais LGBT. Por outro lado, aqueles grupos mais integrados e atuantes junto ao governo e aos programas nacionais, estaduais e municipais de HIV/AIDS saíram fortalecidos.

Monteiro e Villela (2009), ao dialogarem com Frey (2000), argumentam que no interior das políticas públicas estabelecidas a partir e na relação entre Estado e sociedade civil organizada, surgem processos de conflito e de consenso no interior dos espaços políticos. Tais tensionamentos podem ser distinguidos de acordo com o caráter distributivo, redistributivo, regulatório e/ou constitutivo do agente governamental que media a relação com a sociedade civil. O Programa Nacional, ao longo de sua história, fez funcionar as políticas de AIDS por meio da presença de inúmeros quadros que atuaram e conheciam profundamente os movimentos sociais LGBT e suas lideranças. Essa situação auxiliou na percepção e definição de problemas, inserção de determinadas lideranças dos movimentos na agenda governamental de AIDS, elaboração de programas e processos decisórios financeiros, implementação de ações e, finalmente, avaliação da política. Foi por meio da AIDS que as lideranças dos movimentos sociais LGBT no Brasil, sobretudo os gays, aprenderam a transitar nos jogos de elaboração de políticas públicas nas instâncias governamentais e legislativas.

Ao pensarmos as dinâmicas que possibilitaram a visibilidade das agendas políticas LGBT, observamos que os movimentos sociais adotaram, em muito, a fórmula conhecida nos Estados Unidos. Os movimentos sociais estiveram interessados, desde o início, em provar a normalidade de suas identidades sem que, para isto, no geral, questionassem o androcentrismo de suas práticas, a lógica heteronormativa das imagens públicas que projetavam e/ou o racismo de suas políticas ativistas.

A aproximação dos movimentos sociais LGBT com o mercado, as paradas do orgulho são expressões dessa aliança. Sem dúvida, permitiram pluralizar as imagens e desestabilizar, em intensidades diferentes, os discursos hegemônicos de quase todo o século $\mathrm{XX}$ sobre as identidades "homossexuais". Porém, há de se destacar, o mercado promoveu a assimilação da cultura gay, lésbica, bissexual e trans à cultura nacional mais difundida, incentivando de certa forma a diferença de identidade. Entretanto, essa aproximação deu-se apenas nos aspectos em que ela serviu para estabelecer um segmento de mercado ou assimilação de determinado modo de vida.

A visibilidade de gays, bissexuais, lésbicas e trans nos últimos anos, indiscutivelmente, sofreu alterações e, por sua vez, os direitos civis, ainda que limitados, também têm sido 
ampliados. Para que tenham seus direitos civis reconhecidos, as LGBT precisaram tornar-se visíveis no espaço público. Assim, reivindicaram e se apropriaram de identidades e reconstruíram suas performatividades e desejos. Em vários aspectos, negaram e/ou desconstruíram os discursos que as remetiam aos campos da doença, desvio, pecado, submissão e crime. Essas prerrogativas, em maior ou menor grau, constituíram o corpo discursivo dos movimentos sociais e ainda direcionam o LGBT, quase 40 anos após os primeiros diagnósticos do HIV no Brasil.

\section{Considerações finais}

$\mathrm{O}$ vírus do HIV nunca teve pátria e tampouco respeitou as fronteiras. Ele não excluiu e muito menos foi ou é seletivo, ainda que a divulgação inicial dos primeiros casos o tenha carimbado no corpo homossexual. A significação instituída em relação aos portadores foi, contudo, seletiva e excludente. Se recorrermos aos guardados de nossas memórias, podemos, ainda, nos assombrar, como nos diria Jeffrey Weeks (2001), com as imagens que foram difundidas no trato com as pessoas vivendo com AIDS. Ali estavam sendo postos em circulação ensinamentos extremamente preconceituosos que, durante décadas, mediaram as ações dos movimentos sociais LGBT.

Com as políticas de prevenção ao HIV/AIDS, a saúde do corpo e da população vai saindo de um território fixo do campo da medicina para tornar-se algo que é também de preocupação da educação. Se a sexualidade tornou-se um negócio de Estado, como afirmou Weeks (2001), não podemos negar que o vírus HIV também contribuiu para produzir outras realidades expansivas, necessidades e demandas de trabalho. Não podemos negar que foi por meio dessas possibilidades que se abriram aos movimentos sociais e os permitiram pensar o corpo como território de experiências, prazeres, cuidados e autocuidados. Existe uma longa história de resistências, lutas e de redes de solidariedades que nasceram ao redor da epidemia e que carecem de serem contadas.

O vírus HIV mostrou facetas sobre a sexualidade, mas não todas. Realidades outras no campo da pesquisa e redes de solidariedades foram sendo produzidas a favor da dignidade das pessoas que contraíram/contraem o vírus. Essas redes de solidariedades, apostando na vida e na mobilidade dessa vida, foram se constituindo em espaços políticos de lutas, de pesquisas e de debates por aqueles e aquelas que não se conformavam com a moral impressa nos discursos que apresentavam a AIDS como símbolo de morte [como câncer gay]. 
Essas redes de solidariedades nascidas com o HIV/AIDS foram constituindo-se em espaços políticos contra a LGBTfobia ${ }^{19}$. Neste cenário complexo em torno da saúde-doença do corpo e da população, fortifica-se a presença de grupos e subgrupos [considerados minorias] que, até então, se viam alijados dos debates públicos e políticos e dos direitos de gozar e participar da cidadania que se conecta ao estado democrático de direitos.

A partir desses cenários complexos e cambiantes de entrada do vírus HIV e da AIDS em nossas realidades mais íntimas, que assombravam/assombram nossos desejos e segredos com o outro e com nossas subjetividades, estamos avançando e ampliando as redes de solidariedades e afetos em torno dessa questão nos espaços dos movimentos sociais. Entre lutas, negociações, desconstruções e aprendizagens em torno das questões que nos prendem à sexualidade e à saúde-doença do corpo, matriz da sexualidade, ainda temos muito que avançar nas diferentes instituições que controlam e produzem a vida desejada.

\section{LA MOVILIZACIÓN SOCIAL Y RESPUESTA COMUNITARIA LGBT AL SIDA - ITINERARIOS REFLEXIVOS}

Resumen: El artículo se propone de forma más abrangente las redes de solidaridad y la emergencia de grupos y organizaciones no gubernamentales de lesbianas, gays, bisexuales, travestis y transexuales (LGBT) a partir de las luchas comunitarias en respuesta a la epidemia de VIH/Sida en las décadas de 1980 y 90. Para tanto, buscamos inspiración en el estilo ensayístico con el fin de estimular el debate. Todas las consideraciones permiten reafirmar el ensayo como una disertación poco extensa, en la cual el/la autor/a construye su objeto a través de un encadenamiento de razonamientos lógicos y fundamentados que estructuran su argumentación. Anclados en essa idea, entendemos que, si por un lado las primeras personas identificadas con VIH eran hombres gays, reforzando el estigma sobre la población; por otra, las respuestas comunitarias a la epidemia y los rumbos del movimiento LGBT fueron responsables por llevar a la luz el debate sobre las homosexualidades y otros modos disidentes de vivir la heterosexualidad y la(s) masculinidad(es). Consideramos que la sociedad civil fué un importante actor en el enfrentamiento de la epidemia ayudando a la construcción de políticas públicas.

Palabras clave: VIH / SIDA. LGBT. Movimiento Social. Respuesta comunitaria.

\footnotetext{
19 Mesmo discordando, dada a disputa interna nos movimentos sociais que denunciam que o conceito "homofobia" apenas visibiliza as vivências violentas de homens gay, optamos por usar o termo LGBTfobia. Entretanto, pensamos que os conceitos "Homofobia" e "LGBTfobia" não expressam a complexidade que envolve a estrutura heteronormativa, sobretudo, quando a cruzamos com as discussões em torno das performatividades de gênero, misoginia e androcentrismo. Sobre o assunto ver: Caetano, 2016.
} 


\section{Referência}

JORNAL NATIONAL ENQUIRER. Nova Iorque: National Enquirer, 13 de agosto de 1985. Capa.

\section{Referências}

ANDRADE, A. Visibilidade gay, cotidiano e mídia: Grupo Arco-Íris-consolidação de estratégia. Um estudo de caso. 2002. Dissertação (Mestrado em Comunicação) - Universidade de Brasília, Brasília, 2002.

CAETANO, M. Performatividades reguladas: heteronormatividade, narrativas biográficas e educação. Curitiba: Appris, 2016.

CÂMARA, C. Cidadania e orientação sexual: a trajetória do Grupo Triângulo Rosa. Rio de Janeiro: Academia Avançada, 2002.

DICIONÁRIO DA TV GLOBO. Programas de dramaturgia e entretenimentos: projeto memórias das organizações Globo. Rio de Janeiro: Zahar, 2003.

FACCHINI, R. Sopa de letrinhas? Movimento homossexual e produção de identidades coletivas nos anos 90. Rio de Janeiro: Garamond, 2005.

FREY, K. Políticas Públicas: um debate conceitual e reflexões referentes à prática da análise de políticas públicas no Brasil. Planejamento e Políticas Públicas, n. 21, 2000.

GREEN, J. Além do carnaval: a homossexualidade masculina no Brasil do século XX. São Paulo: UNESP, 2000.

"Mais amor e mais tesão": a construção de um movimento brasileiro de gays, lésbicas e travestis. Cadernos Pagu, n.15, p. 271-295, 2000.

HARAWAY, D. Manifesto ciborgue: ciência, tecnologia e feminismo socialista no final do século XX. In: SILVA, Tomaz (Org.). Antropologia do ciborgue: as vertigens do póshumano. Belo Horizonte: Autêntica, 2000.

HOOKS, B. Ensinando a transgredir: a educação como prática da liberdade. São Paulo: WMF Martins Fontes, 2013.

LAURENTI, R. Homossexualismo e a Classificação Internacional de Doenças. Revista de Saúde Pública, São Paulo, v.18, n. 5, out. 1984.

MAC RAE, E. A construção da igualdade: identidade sexual e política no Brasil da abertura. Campinas: Unicamp, 1990

. Os homossexuais, a AIDS e a medicina. Temas Radis, Rio de Janeiro, v. 5, 1987.

Em Defesa do Gueto. Novos Estudos. CEBRAP, São Paulo, v. 2, n. 1, p. 53-60, 1982. 
MONTEIRO, A. L.; VILLELA, W. V. A criação do Programa Nacional de DST e AIDS como marco para a inclusão da idéia de direitos cidadãos na agenda governamental brasileira. Rev. Psicologia Política, São Paulo v. 9, n. 17, jun./ 2009.

MOGROVEJO, N. Un amor que se atrevo a decir su nombre: la lucha de las lesbianas y su relación con los movimientos homosexual y feminista en América Latina. México: Plaza y Valdés, 2008.

PARKER, Richard.; PIMENTA, Cristina (Org). Homossexualidade: produção cultural, cidadania e saúde. Rio de Janeiro: ABIA, 2004.

REVISTA VEJA. São Paulo: Ed. Abril, Edição 1077, Ano 22, No. 17, abril. 1989. Capa. ROSA, J. G. Grandes sertões veredas. Rio de Janeiro: Nova Fronteira, 2001.

WEEKS, J. O corpo e a sexualidade. In: LOURO, G. (Org). O corpo educado: pedagogia da sexualidade. Belo Horizonte: Autêntica. 2001.

SANTOS FILHO, É. Saindo da sombra: o movimento social brasileiro no financiamento entre o Banco Mundial e o Programa Nacional de AIDS. 2002. 177 p. Dissertação (Mestrado em Relações Internacionais). Instituto de Relações Internacionais, Rio de Janeiro, 2002.

SELEM, M. C. O. A Liga Brasileira de Lésbicas: produção de sentidos na construção do sujeito político lésbicas. Revista Estudos feministas. jul/dez. 2007. 